\title{
Post-Traumatic Growth and
} Resilience Among Medical Students In the Wake of COVID-19

CYNTHIA LUO

GABRIEL SANTOS-MALAVE

CRAIG KATZ

ROBERT YANAGISAWA

KANA TAKU (D)

*Author affiliations can be found in the back matter of this article

\section{ABSTRACT}

Background/Rationale: The ongoing COVID-19 pandemic has not only affected the physical wellbeing but also the mental health of many individuals, including young adults such as medical students. Many factors influence a student's ability to cope with and grow from stressful experiences, including their resilience behaviors and traits. Building upon prior studies on post-traumatic growth and resilience in medical students at Fukushima Medical University following their 3/11 disaster, this study broadens the scope by asking medical students at the Icahn School of Medicine at Mount Sinai to identify any life event they recall as being most stressful, including but not limited to COVID-19, and to reflect on their resilience promoting behaviors and post-traumatic growth post-event. Surveying a new population of medical students in New York allows for comparisons of posttraumatic growth and resilience behaviors exhibited by students in Japan and the US. We also hope to identify specific strategies that are commonly used by students to cope with various traumatic experiences.

Hypothesis or research question: The primary goal is to determine factors that contribute to posttraumatic growth and resilience among a cohort of medical students. We hypothesize that medical students who demonstrate greater resilience behaviors will experience less posttraumatic stress. Additionally, we hypothesize that students who indicated that their most impactful life event was a non-COVID event experienced less COVID-related stress.

Study Design/Methods: All consenting medical students at the Icahn School of Medicine at Mount Sinai were anonymously surveyed and asked to reflect on their most stressful life event (Impactful Life Events Survey). In the context of the impactful life event, students were asked to respond to an adapted version of the DavidsonTrauma Scale (DTS); Resilient Behavior Scale (RBS), a Mount Sinai-developed survey examining resilience behaviors across 10 domains; the Post-Traumatic Growth Inventory (PTGI); and the Connor-Davidson Resilience Scale-10 (CDRS-10). Students were also asked to reflect about the impact of COVID-19 on themselves and their
CORRESPONDING AUTHOR:

\section{Cynthia Luo}

Icahn School of Medicine at Mount Sinai, US

cynthia.luo@icahn.mssm.edu

\section{KEYWORDS:}

resilience; COVID-19; mental health; wellness; post-traumatic growth

TO CITE THIS ARTICLE: Luo C, Santos-Malave G, Katz C, Yanagisawa R, Taku K. Post-Traumatic Growth and Resilience Among Medical Students In the Wake of COVID-19. ISMMS Journal of Science and Medicine. 2021; 1(2): 2, pp. 1-4. DOI: https:// doi.org/10.29024/ijsm.49 
families. Optional interviews were conducted to provide qualitative insights into students' experiences. The survey data was analyzed by examining correlations between student demographics, post-traumatic stress, and responses on the RBS, PTGI, and resilience scales. Interview findings were analyzed qualitatively for trends and commonalities shared among students.

Results: We distributed our survey to medical students at the Icahn School of Medicine at Mount Sinai and collected 78 responses. 35 (44.9\%) students indicated that the COVID-19 pandemic was their most impactful life event (ILE), while 43 (55.1\%) students indicated a non-COVID-19 event as their ILE (Figure 1).

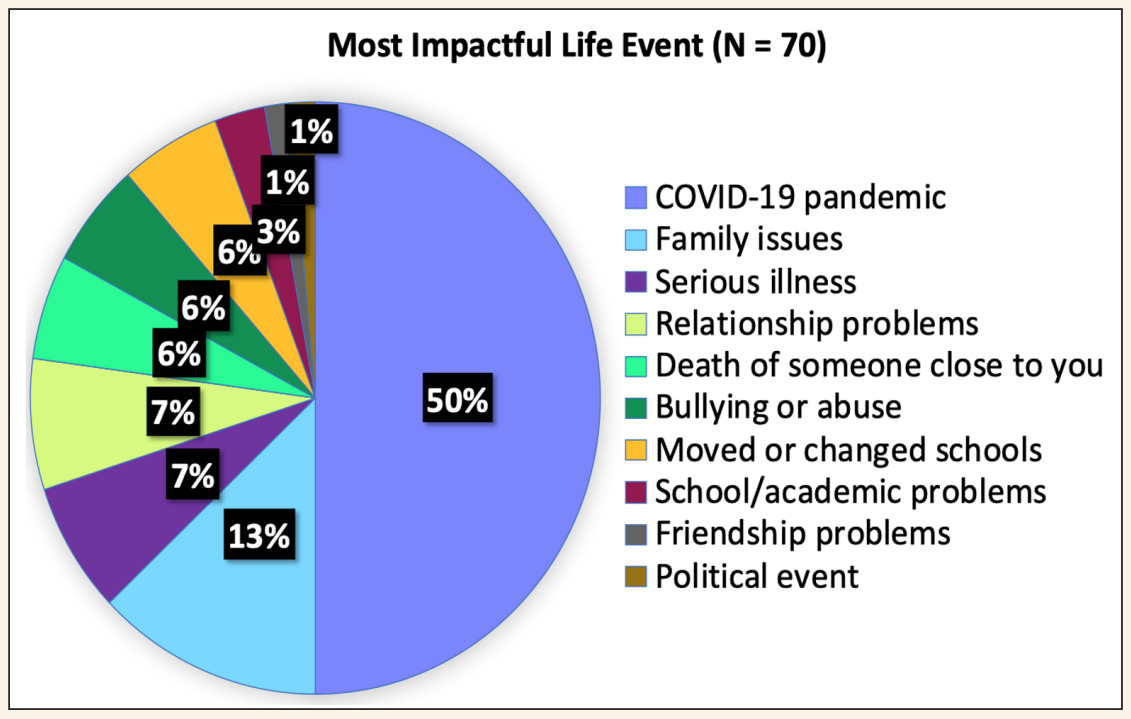

The RBS and CDRS-10 were positively correlated with one another (Pearson correlation $=.533, \mathrm{p}<.001$ ) (Table 1A), and both resilience scales were positively correlated with students who believed there was something positive about COVID-19 (RBS: Pearson correlation $=.26, p=.05 ;$ CDRS-10: Pearson correlation $=.31, p=.017$ ). The RBS was positively correlated with posttraumatic growth (Pearson correlation .455, $p<.001$ ), while the CDRS-10 was not (Table 1B, C).

\begin{tabular}{llll}
\hline \multicolumn{1}{l}{ A } & & CDRS-10 & \\
\hline & & Pearson correlation & $p$ value \\
\hline & RBS-total & 0.533 & $<.001$ \\
\hline B & & CDRS-10 & \\
\hline & & Pearson correlation & $p$ value \\
\hline & PTGI total & 0.029 & 0.827 \\
\hline C & & RBS & \\
\hline & & Pearson correlation & $p$ value \\
\hline & & PTGI total & $<55$ \\
\hline & PTGI-F1: Relating to Others & .339 & 0.001 \\
\hline & PTGI-F2: New Possibilities & .365 & 0.004 \\
\hline & PTGI-F3: Personal Strength & .421 & $<.001$ \\
\hline & PTGI-F4: Spiritual Change & .441 & $<.001$ \\
\hline & PTGI-F5: Appreciation of Life & .28 & 0.029 \\
\hline
\end{tabular}

The highest-rated resilience behaviors used by students to cope included RBS-7: Established and nurtured a supportive social network, RBS-3: Relied on your moral compass, and RBS-2: Used cognitive flexibility through reevaluation of trauma (Table 2). Students who were interviewed similarly expressed that they relied on family, friends, and significant others to cope with stressful life events.
Figure $150 \%$ of students indicated that COVID-19 as their ILE, while 50\% indicated another event as their ILE.

Table 1 RBS and CDRS-10 are positively correlated with each other (A); CDRS-10 is not correlated with posttraumatic growth (B); RBS is positively correlated with posttraumatic growth (C). 
Compared with students who indicated COVID-19 as their ILE, students who indicated a prior, non-COVID ILE experienced less COVID-related stress ( $t=-2.2, p=.03$ ), greater posttraumatic growth ( $t=4.3, p<.001$ ), and more resilient behaviors including establishing and nurturing a supportive social network $(t=2.2, p=.03)$, developing brain fitness $(t=2.2, p=.03)$, and finding meaning and purpose in things $(t=2.9, p=.006)$ (Table 2).

\begin{tabular}{|c|c|c|c|c|}
\hline & $\begin{array}{l}\text { ILE: NON-COVID } \\
(\mathrm{N}=43)\end{array}$ & $\begin{array}{l}\text { ILE: COVID } \\
(\mathrm{N}=35)\end{array}$ & TEST & $\begin{array}{l}p \\
\text { VALUE }\end{array}$ \\
\hline PTGI Total & $M=29.47(10.21)$ & $M=19.24(9.10)$ & $t=4.33$ & $<.001^{* *}$ \\
\hline PTGI-FI: Relating to Others & $M=5.37(3.05)$ & $M=3.57(2.39)$ & $t=2.75$ & $0.008^{* *}$ \\
\hline PTGI-F2: New Possibilities & $M=4.89(2.92)$ & $M=2.31(1.97)$ & $t=4.32$ & $<.001^{* *}$ \\
\hline PTGI-F3: Personal Strength & $M=6.60(3.10)$ & $M=3.46(2.69)$ & $t=4.53$ & $<.001^{* *}$ \\
\hline PTGI-F4: Spiritual Change & $M=5.35(2.55)$ & $M=3.52(2.49)$ & $t=2.99$ & $0.004^{* *}$ \\
\hline $\begin{array}{l}\text { RBS-7: Est supportive social } \\
\text { network }\end{array}$ & $M=3.09(0.78)$ & $M=2.61(0.88)$ & $t=2.18$ & $0.033^{* *}$ \\
\hline $\begin{array}{l}\text { RBS-8: Attended to physical } \\
\text { wellbeing }\end{array}$ & $M=2.25(1.15)$ & $M=1.99(1.02)$ & $t=0.9$ & 0.372 \\
\hline RBS-9: Developed brain fitness & $M=2.79(0.93)$ & $M=2.28(0.88)$ & $t=2.17$ & $0.034^{* *}$ \\
\hline $\begin{array}{l}\text { RBS-10: Found and fostered } \\
\text { strengths }\end{array}$ & $M=2.64(1.04)$ & $M=2.27(0.90)$ & $\mathrm{t}=1.45$ & 0.153 \\
\hline $\begin{array}{l}\text { RBS-11: Found meaning and } \\
\text { purpose in things }\end{array}$ & $M=2.69(0.99)$ & $M=1.99(0.87)$ & $\mathrm{t}=2.87$ & $0.006^{* *}$ \\
\hline COVID Stress Symptoms & $M=8.39(5.65)$ & $M=13.1(3.99)$ & $t=-2.24$ & $0.029 * *$ \\
\hline
\end{tabular}

Conclusions/Future Plans: Given the ongoing COVID-19 pandemic and its effects on mental health, understanding how young adults respond to this and other stressful life events is essential. We identified specific resilience behaviors and traits that medical students commonly used to cope with traumatic experiences. Additionally, we demonstrated that the RBS and CDRS-10 likely measure different aspects of resilience, since only the RBS was positively correlated with posttraumatic growth. Finally, we found that students who chose a non-COVID event as their ILE demonstrated greater posttraumatic growth, greater resilience behaviors, and less COVID-19 stress than students who indicated COVID-19 as their ILE. This suggests that stressful experiences prior to or in parallel to COVID encourage posttraumatic growth and development of resilience behaviors that are protective factors to COVID-19-related stress.
Luo et al.

ISMMS Journal of Science

and Medicine

DOI: $10.29024 / \mathrm{ijsm} .49$

Table 2 Students who indicated a non-COVID impactful life event (ILE) demonstrated significantly** greater posttraumatic growth (PTGI), resilience behaviors (RBS), and less COVID-19 stress symptoms than students who indicated COVID-19 as their ILE.

\section{COMPETING INTERESTS}

The authors have no competing interests to declare.

\section{AUTHOR AFFILIATIONS}

\section{Cynthia Luo}

Icahn School of Medicine at Mount Sinai, US

\section{Gabriel Santos-Malave Santos-Malave}

Icahn School of Medicine at Mount Sinai, US

\section{Craig Katz}

Icahn School of Medicine at Mount Sinai, US

\section{Robert Yanagisawa}

Icahn School of Medicine at Mount Sinai, US

Kana Taku (iD) orcid.org/0000-0003-1515-7951

Oakland University, US 
ISMMS Journal of Science

and Medicine

DOI: $10.29024 / \mathrm{ijsm} .49$

TO CITE THIS ARTICLE:

Luo C, Santos-Malave G, Katz C, Yanagisawa R, Taku K. Post-Traumatic Growth and Resilience Among Medical Students In the Wake of COVID-19. ISMMS Journal of Science and Medicine. 2021; 1(2): 2, pp. 1-4. DOI: https:// doi.org/10.29024/ijsm.49

Submitted: 13 April 2021

Accepted: 13 April 2021

Published: 29 April 2021

\section{COPYRIGHT:}

(c) 2021 The Author(s). This is an open-access article distributed under the terms of the Creative Commons Attribution 4.0 International License (CC-BY 4.0), which permits unrestricted use, distribution, and reproduction in any medium, provided the original author and source are credited. See http://creativecommons.org/ licenses/by/4.0/.

ISMMS Journal of Science and Medicine is a peer-reviewed open access journal published by Levy Library Press. 